\title{
Task-Specific Ionic Liquid Enables Highly Efficient Low Temperature Desalination by Directional Solvent Extraction
}

\author{
Jiaji Guo, ${ }^{a}$ Zachary D. Tucker, ${ }^{b}$ Yu Wang, ${ }^{a}$ Brandon L. Ashfeld, ${ }^{* b}$ Tengfei Luo*a,c \\ a Department of Aerospace and Mechanical Engineering, University of Notre Dame, Notre Dame, IN \\ 46556. Email: tluo@nd.edu \\ ${ }^{b}$ Department of Chemistry and Biochemistry, University of Notre Dame, Notre Dame, IN 46556. \\ Email: bashfeld@nd.edu \\ c Department of Chemical and Biomolecular Engineering, University of Notre Dame, Notre Dame, IN \\ 46556
}




\begin{abstract}
Seawater desalination plays a critical role in addressing the global water shortage challenge, and directional solvent extraction (DSE) is an emerging desalination technology to address this challenge. Herein, we demonstrate that through a combination of target-directed synthesis and computational simulations, task-specific ionic liquids (ILs) may significantly advance current DSE technology by improving the energy efficiency toward impacting the global waterenergy nexus.
\end{abstract}

The shortage of viable water resources is rapidly reaching critical status on a global scale. While extended droughts in many areas is a contributing factor, $^{1}$ industrial and residential pollution of regional and local water supplies exacerbates this growing crisis. Given that ocean and subterranean saline aquifers contain $97.5 \%$ of the global water, desalination is a promising means for meeting fresh water demand. While membrane-based desalination processes like reverse osmosis (RO) have drawn considerable attention, the need for high grid electricity renders their application in lowresource settings challenging. ${ }^{2}$ RO can be energy-efficient (as low as $2 \mathrm{kWh} / \mathrm{m}^{3}$ ) in centralized plants largely due to the implementation of mechanical energy recovery systems, ${ }^{3}$ but at smaller scales, the energy cost can be much higher (up to $17 \mathrm{kWh} / \mathrm{m}^{3}$ ). ${ }^{4}$ In contrast, directional solvent extraction (DSE), named one of the top ten world-changing ideas by Scientific American in 2012, ${ }^{5}$ is an attractive alternative as it requires comparatively low operation temperatures relying almost exclusively on the consumption of waste heat or unconcentrated solar energy. ${ }^{6,} 7$ The conceptual basis behind DSE centers on the use of a task-specific directional solvent (DS) that can solvate water in high yield, defined as the water solubility change per degree of temperature change $\left(\% /{ }^{\circ} \mathrm{C}\right)$, is insoluble in water, and will not solvate salt ions..$^{6-8}$ It has been proposed that these directional solubilities are a result of the subtle balance between the hydrophilic and hydrophobic features of the solvent and the resulting intermolecular interactions with the solute. ${ }^{7}$ Not surprisingly, a major impediment to the implementation of DSE processes is the identification of an optimal DS. Currently, decanoic acid, with a water yield of $0.027 \% /{ }^{\circ} \mathrm{C}$, represents the best performing DS to date. ${ }^{9}$ This exceptionally low yield results in a low water production rate and relatively high energy consumption. ${ }^{6}$ In contrast to aliphatic acids, we speculated that a readily functionalized heteroaromatic core would enable the desirable balance of hydrophobic and hydrophilic properties amenable to optimal DS performance. While tuning hydrophilicity of solids has been investigated that can contribute to thermal desalination, ${ }^{10-12}$ studies of liquid phase hydrophilicity for similar purposes have not been seen. Herein, we report the identification of an $\mathrm{N}$-aheterocyclic task-specific ionic liquid (TSIL) for DSE, discovered through the combined use of experiments and molecular dynamics (MD) simulations, that exhibits a ten-fold improvement in fresh water yield over decanoic acid.

Ionic liquids (ILs) have demonstrated exceptional promise as a molecular framework for the development of task-specific fluids due to their design flexibility and inherently low volatility. ILs comprised of organic ions residing in a liquid state between room temperature and $100{ }^{\circ} \mathrm{C}$ have shown promise as working fluids across a variety of applications, including the separation of organic compounds, sequestration of transition metals, capturing carbon dioxide, and desalinating aqueous media. ${ }^{13-17}$ The structural versatility and variability of many ILs enable extraordinary freedom in solvent design, as the cation and anion components can be individually engineered to achieve the desired directional solubilities. As illustrated in Figure 1, an optimal DS IL would display sparing solubility with highly concentrated salt water (a), which then

a 
upon heating, draws only water into the IL while leaving the salts in the water phase yielding a high salinity brine $(\mathrm{MX})(b)$. Removal of the $M X$ byproduct $(c)$ followed by a reduction in temperature leads to decreased solubility of water in the IL $(d)$ that could then be readily separated to provide the desired fresh water. Upon separation, the recovered IL is recycled for subsequent process turnover of the DSE cycle (e). Given the variable water and salt solubility of many ILs, we were faced with the challenge of identifying a working fluid that would accommodate each phase of this DSE cycle.

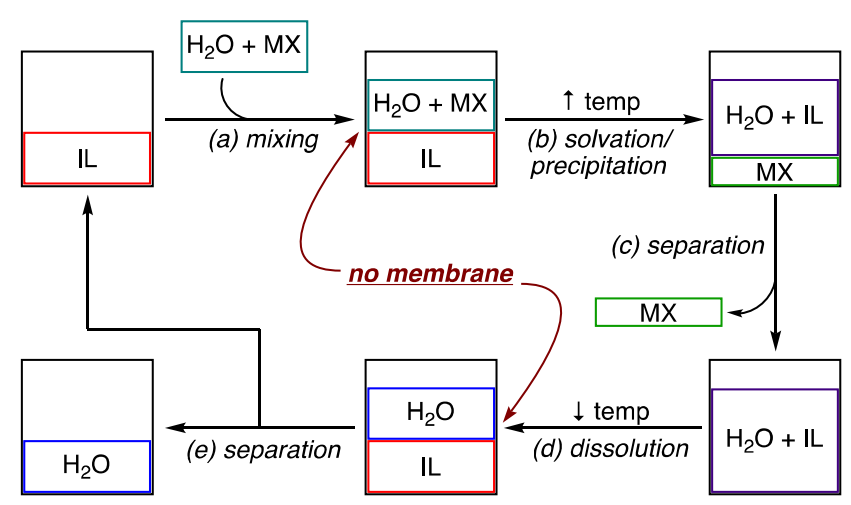

Figure 1. DSE desalination employing TSILs.

Inspired by a recent report by Cai and coworkers $^{18}$ that demonstrated the feasibility of phosphonium sulfonate ILs as draw solutions for low temperature forward osmosis (FO), we began our study by examining a series of sulfonate anion-based TSILs as DSs for DSE desalination. We initially targeted the $p$-toluene sulfonate anion salts of tetrabutylphosphonium IL $\left[\mathrm{P}_{4444}\right][\mathrm{TSO}]$, and the corresponding 1-ethyl-3methylimidazolium-based IL [emim][TsO] was also synthesized due to the well-established physical attributes of the imidazolium ILS (Figure 2). Similarly, the imide anion-based ILS $\left[\mathrm{P}_{4444}\right]\left[\mathrm{Tf}_{2} \mathrm{~N}\right]$ and [emim] $\left[\mathrm{Tf}_{2} \mathrm{~N}\right]$ were assembled in an effort to evaluate the relatively non-polar characteristics of the bistriflimide component. To determine the impact of changes in IL hydrophobicity, density and viscosity on DSE performance, we incorporated two different alkyl chain lengths in the phosphonium and imidazolium cations to provide the unsymmetrical ILs $\left[\mathrm{P}_{4448}\right]\left[\mathrm{Tf}_{2} \mathrm{~N}\right]$ and [bmim] $\left[\mathrm{Tf}_{2} \mathrm{~N}\right]$. Each targeted IL was readily synthesized using a salt metathesis approach wherein alkylation of either the parent $N$-methyl 3 imidazole or $\mathrm{P}^{n} \mathrm{Bu}_{3}$ with the desired alkyl iodide or bromide followed by anion exchange to incorporate the desired sulfonate or bistriflimide anions. Alternatively, treatment of the tetraalkyl phosphonium bromide with $\mathrm{KOH}$ in $\mathrm{MeOH}$ followed by exposure to the sulfonic acid or triflimide provided the desired phosphonium ILs. Each IL was obtained in excellent yield and evaluated using ion exchange chromatography and Karl-Fisher titration for residual halide and water content respectively. Synthesis and characterization details of the ILs are included in Section 1 in the Supplemental Information (SI).

$$
\begin{aligned}
& \text { phosphonium-based ILs } \\
& \oplus_{\mathrm{P}^{n} \mathrm{Bu}_{4}}^{p-\mathrm{TsO}^{\ominus}} \\
& \text { [ } \left.\mathbf{P}_{4444}\right][\mathrm{TsO}] \\
& \underset{\mathrm{P}^{n} \mathrm{Bu}_{4}}{\mathrm{Tf}_{2} \mathrm{~N}} \Theta \\
& {\left[\mathrm{P}_{4444}\right]\left[\mathrm{Tf}_{2} \mathrm{~N}\right]}
\end{aligned}
$$

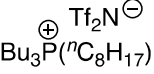

$$
\begin{aligned}
& \text { idazolium-based ILs } \\
& \sum_{N}^{\mathrm{Et}} \oplus p-\mathrm{TsO}^{\ominus} \\
& \text { [emim][TsO] } \\
& \sum_{N}^{\mathrm{Et}} \sum_{\mathrm{Me}}^{\mathrm{E}} \mathrm{Tf}_{2} \mathrm{~N}^{\ominus} \\
& \text { [emim][Tf } \left.{ }_{2} \mathrm{~N}\right] \\
& {\left[\mathrm{P}_{4448}\right]\left[\mathrm{Tf}_{2} \mathrm{~N}\right]}
\end{aligned}
$$

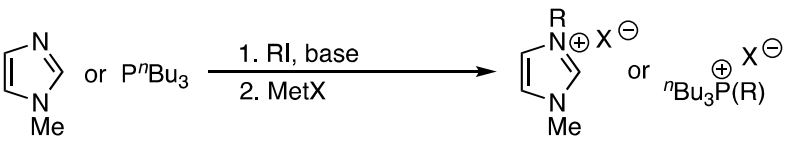

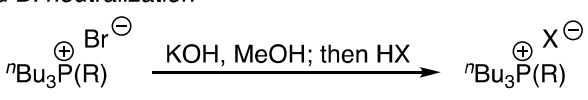

Figure 2. Assembling the TSILS for DSE evaluation.

The DS performance in a DSE desalination cycle was evaluated for the assembled ILs, which involved first exposure to water bearing 3.7-5.0 wt\% of $\mathrm{NaCl}(11,000-15,000 \mathrm{ppm}$ of $\mathrm{Na}^{+}$) followed by thorough mixing at elevated temperatures of 45,60 or $75{ }^{\circ} \mathrm{C}$ (see Section 2 in the SI for experimental details). The mixture was held for $\sim 10$ mins at each stage to allow for complete phase separation. We note that for the most promising IL ([emim][ $\left.\left.\mathrm{Tf}_{2} \mathrm{~N}\right]\right)$ identified, a settling time as low as 2-min was found sufficient. The water-enriched IL phase was then removed and allowed to cool to room temperature, which resulted in a second separation of the IL and desalinated water. The amount of residual $\mathrm{NaCl}$ and IL in the recovered 
aqueous phase was then measured using atomic emission spectroscopy and liquid chromatography-mass spectrometry (see Section 3 in the SI for details).

Of the characterized ILs, two were identified as potentially viable frameworks for DSE, and their DSE-relevant solubilities are shown in Table 1 with decanoic acid as the comparable standard. Those ILs not shown underwent an undesirable salt metathesis with saline water, exhibited a prohibitively high melting temperature, or exceptionally high viscosity (see Section 4 in SI for the list of ILS incompatible with DSE). Curiously, the phosphonium-based ILs either resulted in the instant precipitate formation, presumably a result of a metathesis reaction with $\mathrm{NaCl}$ to provide the corresponding $\left[\mathrm{P}_{444 \mathrm{R}}\right]$ [Cl] salt, or exhibited physical properties incompatible with DSE (e.g., melting point $>65$ ${ }^{\circ} \mathrm{C}$, high viscosity, etc.). While the imidazolium IL [emim][TsO] also induced a salt metathesis reaction, the bistriflimide [emim] $\left[\mathrm{Tf}_{2} \mathrm{~N}\right]$ exhibited exceptional ion rejection at $>96 \%$ with low solubility in water in the range of 130 $150 \mathrm{ppm}$ and a surprisingly high-water yield of $0.3 \% /{ }^{\circ} \mathrm{C}$ (Table 1). In contrast, $[$ bmim $]\left[\mathrm{Tf}_{2} \mathrm{~N}\right]$ provided a significantly lower water yield of $<0.082 \% /{ }^{\circ} \mathrm{C}$ despite a reasonable ion rejection rate of $\sim 70 \%$ and favorable solubility in water $(<90 \mathrm{ppm})$.

Table 1. TSIL DSE Desalination Performance $^{a}$

\begin{tabular}{|c|c|c|c|}
\hline $\mathrm{IL}$ & $\begin{array}{c}\text { Ion } \\
\text { Rejection }\end{array}$ & $\begin{array}{c}\mathrm{H}_{2} \mathrm{O} \\
\text { Solubility } \\
(\mathrm{ppm})\end{array}$ & $\begin{array}{c}\mathrm{H}_{2} \mathrm{O} \\
\text { Yield } \\
\left(\% /^{\circ} \mathrm{C}\right)\end{array}$ \\
\hline $\begin{array}{c}{[\mathrm{bmim}]} \\
{\left[\mathrm{Tf}_{2} \mathrm{~N}\right]}\end{array}$ & $70.5 \% \pm 2.9 \%$ & $<90$ & $<0.08$ \\
\hline$[e m i m]$ & $97.5 \% \pm 0.8 \%$ & $130-150$ & 0.304 \\
{$\left[\mathrm{Tf}_{2} \mathrm{~N}\right]$} & & & \pm \\
\hline $\begin{array}{c}\text { decanoic } \\
\text { acid }\end{array}$ & $\begin{array}{c}96.9 \% \sim 98.0 \\
\%^{6}\end{array}$ & $36-150^{6,19}$ & 0.023 \\
\hline & & & $\begin{array}{c}0.025 \\
\pm 0.00\end{array}$ \\
\hline
\end{tabular}

a ILS found incompatible with DSE are shown in Section 4 in SI.
Given the promising ion rejection rate, water solubility, and water yield exhibited by [emim] $\left[\mathrm{Tf}_{2} \mathrm{~N}\right]$, we next examined the fresh water recovery of this $\mathrm{IL}$ at elevated temperatures. Exposure of [emim] $\left[\mathrm{Tf}_{2} \mathrm{~N}\right]$ to a $3.7 \mathrm{wt} \% \mathrm{NaCl}$ saline feed at 45,60 , and $75{ }^{\circ} \mathrm{C}$ revealed an average water yield of $0.3 \pm 0.023 \% /{ }^{\circ} \mathrm{C}$ (Figure 3a). As is evident, the exceptional water yield displayed by [emim] $\left[\mathrm{Tf}_{2} \mathrm{~N}\right]$ in comparison to decanoic acid supports our supposition that ILbased DSs constitute a viable class of soft materials toward the development of more efficient DSE desalination process. ${ }^{8}$

For saline with $\mathrm{NaCl}$ salinity in the range of 3.0$3.8 \mathrm{wt} \%\left(11,000-15,000 \mathrm{ppm}\right.$ of $\left.\mathrm{Na}^{+}\right)$, [emim] $\left[\mathrm{Tf}_{2} \mathrm{~N}\right]$ exhibited outstanding ion rejection rates of $97.0-98.3 \%$ (Figure $3 \mathrm{~b}$ ), bringing the salt content below the drinking water standard of $500 \mathrm{ppm} .{ }^{20}$ To test the capacity of [emim] $\left[\mathrm{Tf}_{2} \mathrm{~N}\right]$ as a DS to treat high salinity water, we conducted several DSE cycle experiments using $10.8 \mathrm{wt} \%$ aqueous $\mathrm{NaCl}$ solution $(42,600 \mathrm{ppm}$ of $\mathrm{Na}^{+}$) as the feed saline. Gratifyingly, we observed an ion rejection rate of $96.0-96.8 \%$ even when [emim] $\left[\mathrm{Tf}_{2} \mathrm{~N}\right]$ was exposed to high concentrations of aqueous $\mathrm{NaCl}$. These results would indicate that $[\mathrm{emim}]\left[\mathrm{Tf}_{2} \mathrm{~N}\right]$ exhibits promising physical attributes to conduct desalination of water at both moderate and high salinity. Additionally, the water yield of [emim] $\left[\mathrm{Tf}_{2} \mathrm{~N}\right]$ is consistent over a temperature range of $45-75{ }^{\circ} \mathrm{C}$, which suggests that low quality waste heat may be suitable to power this desalination process.
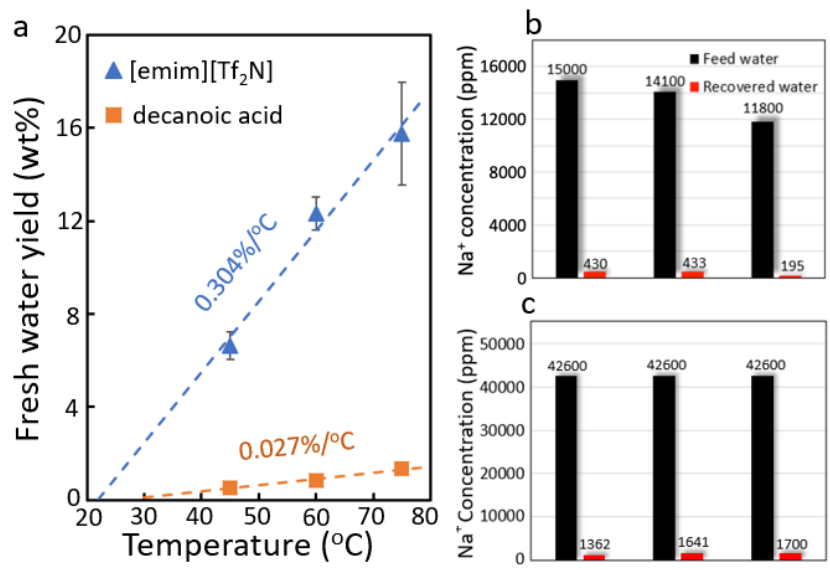

Figure 3. (a) Water yield and temperature relationship of [emim] $\left[\mathrm{Tf}_{2} \mathrm{~N}\right]$ and decanoic acid. Error bar is the standard deviation of different 
tests for each condition. (b) Desalination of moderate salt content water (3.7-5.0 wt\%). (c) Desalination of high salt content water (10.8 wt $\%)$. Each set of bars in (b) and (c) corresponds to one batch of experiment.

Employing molecular dynamics (MD) simulations in combination with thermodynamic integration to calculate the solvation free energies at room temperature for $\mathrm{NaCl}$, water, and [emim] $\left[\mathrm{Tf}_{2} \mathrm{~N}\right]$, we sought to gain a molecular level understanding of those experimentally observed directional solubilities. In brief, a solute molecule (e.g., $\mathrm{Na}^{+}$or $\mathrm{H}_{2} \mathrm{O}$ ) is simulated to "gradually appear" into the solution, and free energy needed for this process is calculated as the solvation free energy. ${ }^{21}$ Details of the simulations are discussed in Sections 5 and 6 in SI. By comparing the solvation free energies, we were able to determine thermodynamic stability in the respective environments for each solute molecule, which ultimately aided our understanding of the variable solvation tendencies. The calculated solvation free energy of $\mathrm{Na}^{+}$in [emim] $\left[\mathrm{Tf}_{2} \mathrm{~N}\right.$ ] is $-389 \mathrm{KJ} / \mathrm{mol}$, which is in contrast to $-415 \mathrm{KJ} / \mathrm{mol}$ found for $\mathrm{Na}^{+}$in water. ${ }^{22}$ This indicates that the salt ions favor solvation in the aqueous media over the corresponding IL phase, and rationalizes the observed ion rejection capability of [emim] $\left[\mathrm{Tf}_{2} \mathrm{~N}\right]$ in the DSE process. Similarly, the solvation free energy of water in [emim] $\left[\mathrm{Tf}_{2} \mathrm{~N}\right]$ of $-28.53 \mathrm{KJ} / \mathrm{mol}$ is less than that of water in water $\left(-26.9 \mathrm{KJ} / \mathrm{mol}^{6}\right)$, which is consistent with the observed propensity for water to dissolve into the IL. Additionally, the calculated solvation free energy of $133 \mathrm{KJ} / \mathrm{mol}$ for [emim] $\left[\mathrm{Tf}_{2} \mathrm{~N}\right]$ in itself is significantly less than that of [emim] $\left[\mathrm{Tf}_{2} \mathrm{~N}\right]$ in water $(180 \mathrm{KJ} / \mathrm{mol})$, which suggests that it is thermodynamically unfavorable for the IL to dissolve in water. Thus, these calculations are consistent with our experimental observations revealing that [emim] $\left[\mathrm{Tf}_{2} \mathrm{~N}\right]$ displays favorable DS thermodynamic properties of water insolubility while concurrently capable of solvating water molecules and rejecting salt ions.

The ability to operate a DSE process at the relatively mild temperatures shown with [emim] $\left[\mathrm{Tf}_{2} \mathrm{~N}\right.$ ] (e.g., $45{ }^{\circ} \mathrm{C}$ ) constitutes a significant advantage wherein waste heat is a viable source of operating power. Exergy is the maximum amount of extractable work from a heat source with Carnot efficiency, and is a useful measure of the overall system efficiency when comparing different desalination technologies. ${ }^{6,23}$ As shown in Figure 4 (details of exergy calculation in Section 7 of $\mathrm{SI}$ ), exergy consumptions of DSE with [emim] $\left[\mathrm{Tf}_{2} \mathrm{~N}\right]$ and decanoic acid both increase with increasing heat source temperature. A DSE process operated with [emim] $\left[\mathrm{Tf}_{2} \mathrm{~N}\right]$ has an exergy cost of $2.4 \mathrm{kWh} / \mathrm{m}^{3}$ at $45{ }^{\circ} \mathrm{C}$ and $5.9 \mathrm{kWh} / \mathrm{m}^{3}$ at 75 ${ }^{\circ} \mathrm{C}$. The pumping power requirement is $0.31 \mathrm{kWh} / \mathrm{m}^{3}$ at $45{ }^{\circ} \mathrm{C}$, and this value will be smaller at higher temperature, according to another study ${ }^{24}$ (details of pumping power calculation in Section 8 of SI). Comparing the exergy consumptions of DSE processes reveals a staggering reduction in exergy cost by $70 \%$ at $45{ }^{\circ} \mathrm{C}$ when [emim] $\left[\mathrm{Tf}_{2} \mathrm{~N}\right]$ is employed as the DS in contrast to decanoic acid. ${ }^{6}$ Additionally, this observed exergy penalty reduction increases to $89 \%$ at $75{ }^{\circ} \mathrm{C}$. Exergy consumption of a state-of-the-art thermal desalination technology - multi-stage flash (MSF) ${ }^{4}{ }^{25-29}$ is also provided for comparison. Besides the advantage of utilizing lower temperature (45$75^{\circ} \mathrm{C}$ ) heat sources compared to MSF $\left(>85^{\circ} \mathrm{C}\right)$, the exergy consumption of DSE using [emim] $\left[\mathrm{Tf}_{2} \mathrm{~N}\right]$ is significantly lower than that of the MSF. While decanoic acid exhibits comparable performance advantages over MSF, these are only realized at operating temperatures below $\sim 55{ }^{\circ} \mathrm{C}$ (Figure 4). We note that ref. $\left[{ }^{3}\right]$ reported that an energy consumption as low as $2 \mathrm{KWh} / \mathrm{m}^{3}$ from new large-scale RO plants might be achieved. Another study ${ }^{30}$ showed that in the state-of-the-art RO plants, the energy cost related to the RO process alone, excluding those from processes like pre-treatment and water delivery, is $2.54 \mathrm{kWh} / \mathrm{m}^{3}$. As a result, DSE has similar energy cost as RO when operating at low temperature, let alone its unique capability of harvesting low temperature waste heat. Moreover, DSE will be suitable for small scale application, especially for low-resource settings, where the energy cost for small-scale RO is high (up to $17 \mathrm{kWh} / \mathrm{m}^{3}$ ), ${ }^{4}$ largely due to the lack of centralized infrastructures for mechanical engineering recovery. 


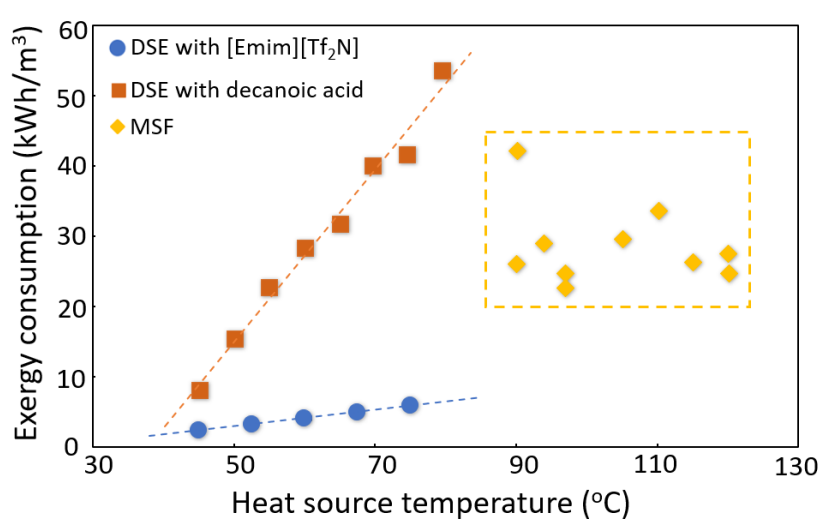

Figure 4. Comparison of exergy consumption of DSE using [emim] $\left[\mathrm{Tf}_{2} \mathrm{~N}\right]$ and decanoic acid and MSF. Propagated from the data uncertainty from Fig. 3 , the calculated uncertainty of the blue data points ranges from $20 \%$ (at $45^{\circ} \mathrm{C}$ ) to $17 \%\left(75^{\circ} \mathrm{C}\right.$ ).

While residual [emim] $\left[\mathrm{Tf}_{2} \mathrm{~N}\right]$ in the recovered water should be low (130-150 ppm), there is no established toxicity standard for this IL in drinking water. To completely remove and recover all IL from the produced water, we can use nanofiltration (NF) as implemented by Cai et al. ${ }^{18}$ and Elimelech et al. $^{3}$ for their IL-FO desalination for similar residue removal purposes. It will also eliminate the loss of IL during operation. The exergy cost for the NF process is a mere $0.011 \mathrm{KWh} / \mathrm{m}^{3}$ given the low osmotic pressure associated with a minimal concentration of residual IL, thereby avoiding a significant energy penalty (see Section 7 in SI for calculation details).

The efficacy of IL-based DSs appear to be modulated dramatically by structural perturbations of the IL. The optimal IL discovered being [emim] $\left[\mathrm{Tf}_{2} \mathrm{~N}\right]$ contains small alkyl chains adorned on the imidazolium cation and a hydrophobic resonance stabilized bistriflimide anion. Conversely, the ILs which failed to provide DSE behavior contain structural features altering hydrophobicity, size, and charge dispersion of the anion and cation. As in the case of [emim][OTs], which contains the larger [OTs] anion in comparison to $\left[\right.$ emim] $\left[\mathrm{Tf}_{2} \mathrm{~N}\right]$, a precipitate was observed upon subjection to a DSE cycle, presumably a mixture of [emim][Cl] and [Na][OTs]. We attribute the failure in DSE behavior to [emim]
[OTs], forming less intimate ion pair allowing for salt metathesis reactions to become more favorable. In addition, both components of [emim][OTs] contain aromatic systems, which may lead to poor water solubility. The [bmim] $\left[\mathrm{Tf}_{2} \mathrm{~N}\right] \mathrm{IL}$ while providing moderate DSE behavior, failed to reject $\mathrm{NaCl}(\sim 70 \%)$ as efficiently as [emim] $\left[\mathrm{Tf}_{2} \mathrm{~N}\right]$ or decanoic acid and has lower solubility in water $(<90 \mathrm{ppm})$ as well as water yield $\left(0.082 \% /{ }^{\circ} \mathrm{C}\right)$, which we attest to the lengthened aliphatic chain. The $[\mathrm{bmim}]^{+}$ cation has an increased hydrophobicity due to increased chain length as well as a weaker cation-anion interaction as longer aliphatic chain lengths present larger steric interaction with the $\left[\mathrm{Tf}_{2} \mathrm{~N}\right]^{-}$anion. Therefore, a stronger interaction may be achieved between [bmim] $[\mathrm{Cl}]$ and $[\mathrm{Na}]\left[\mathrm{Tf}_{2} \mathrm{~N}\right]$ due to the relative size differences yielding more intimate ion pairs sequestering more $\mathrm{NaCl}$. As a result, the salt rejection rate is only around $70 \%$ according to our tests. It, however, might be used for treating low salinity water ( $<1600 \mathrm{ppm})$, where the $70 \%$ ion rejection rate can bring the salinity down to meet the drinking water standard of $500 \mathrm{ppm}$.

In comparison to the imidazolium-based cations whose positive charge is resonated into the aromatic system, the tetraalkyl phosphonium cations have a point charge dispersed over a smaller area (See Section 1 in SI for tetraalkyl phosphonium-based ILs used in this study). This difference in polarization alters ion-pair strength, which may be responsible for the decrease in the desired DS behavior of tetralkyl phosphonium ILs, where larger charge separation weakens the interion interactions of the IL, allowing large amounts of sodium chloride to penetrate into the IL phase leading to undesired metathesis reactions. In addition to size and charge distribution, the viscosity of the IL affects the DSE behavior. For example, the ion rejection rate is found to be very low for $\left[\mathrm{P}_{4448}\right]\left[\mathrm{Tf}_{2} \mathrm{~N}\right]$, (The concentration of recovered water is even higher than the feed water.) whose viscosity is $0.433 \mathrm{~Pa} \cdot \mathrm{s}$, which is very high (See Section 4 in SI for viscosity of the ILs). Furthermore, high viscosity ILs are not optimal for practical applications as a large pumping power would be required to perform a DSE cycle. 
In this work, we demonstrate that DSE can effectively remove $\mathrm{NaCl}$ from water by using [emim] $\left[\mathrm{Tf}_{2} \mathrm{~N}\right]$. The DSE technique, which can utilize the low temperature heat, can potentially result in low resource setting applications. By analyzing the results of several tested ILs and their DSE behavior, we have also rationalized the chemistry-property relation, which might be helpful for further identification of task specific DS ILs. The work is also expected to further stimulate research around the DSE technology.

\section{Associated content}

The Supporting Information is available free of charge on the ACS Publications website.

The Supporting Information includes synthesis and characterization of ILS, DSE experimental screening of candidate ILs, molecular dynamics simulation details, free energy calculation, concentration of measurement of $\mathrm{NaCl}$ and ILS and list of ILs tested in experiment (PDF).

\section{Author information}

Corresponding Author

*tluo@nd.edu

*bashfeld@nd.edu

\section{Conflicts of interest}

The authors declare no competing financial interest.

\section{Acknowledgements}

This research was supported by National Science Foundation (1510826 and CHE 1665440). We would like to thank the Center for Environmental Science and Technology (CEST) for facilitating measurement of the $\mathrm{NaCl}$ and IL concentrations. The simulation is partially supported by the Center for Research Computing at the University of Notre Dame and the NSF through XSEDE computing resources provided by TACC Stampede-2 under Grant No. TG-CTS100078. T.L. would also like to thank the Dorini Family for the endowed professorship in energy studies.

\section{References}

1. Mancosu, N., Snyder, R., Kyriakakis, G. \& Spano, D. Water scarcity and future challenges for food production. Water 7, 975-992 (2015).

2. Marks, D. et al. Review of the Desalination and Water Purification Technology Roadmap. National Research Council, National Academies Press, Washington, DC (2004).

3. Elimelech, M. \& Phillip, W. A. The future of seawater desalination: energy, technology, and the environment. Science 333, 712-717 (2011).

4. Thomas, K. E. Overview of village scale, renewable energy powered desalination (1997).

5. Jabr, F. et al. WORLD CHANGING IDEAS. Sci. Am. 307, 34-45 (2012).

6. Bajpayee, A., Luo, T., Muto, A. \& Chen, G. Very low temperature membrane-free desalination by directional solvent extraction. Energy \& Environmental Science 4, 1672-1675 (2011).

7. T.Luo, A. B., G.Chen. Directional solvent for membrane-free water desalination-A molecular level study. Journal of Applied Physics 110, 054905 (2011).

8. Davidson, R., Smith Jr, W. \& Hood, D. W. Structure and Amine-Water Solubility in Desalination by Solvent Extraction. J. Chem. Eng. Data 5, 420-423 (1960).

9. Hoerr, C., Pool, W. \& Ralston, A. The effect of water on the solidification points of fatty acids. Solubility of water in fatty acids. Oil \& Soap 19, 126128 (1942).

10. Xiao, R., Maroo, S. C. \& Wang, E. N. Negative pressures in nanoporous membranes for thin film evaporation. Appl. Phys. Lett. 102, 123103 (2013).

11. Rangharajan, K. K., Sundaram, P. M., Conlisk, A. \& Prakash, S. Surface dependent enhancement in water vapor permeation through nanochannels. Analyst 143, 4256-4266 (2018).

12. Pang, Y. et al. Solar-Thermal Water Evaporation: A Review. ACS Energy Letters (2020).

13. Lei, Z., Chen, B., Koo, Y. \& MacFarlane, D. R. Introduction: ionic liquids (2017).

14. Ventura, S. P. et al. Ionic-liquid-mediated extraction and separation processes for bioactive compounds: past, present, and future trends. Chem. Rev. 117, 6984-7052 (2017).

15. Sarmad, S., Mikkola, J. \& Ji, X. Carbon dioxide capture with ionic liquids and deep eutectic solvents: a new generation of sorbents. ChemSusChem 10, 324-352 (2017). 
16. Hallett, J. P. \& Welton, T. Room-temperature ionic liquids: solvents for synthesis and catalysis. 2. Chem. Rev. 111, 3508-3576 (2011).

17. Lei, Z., Dai, C. \& Chen, B. Gas solubility in ionic liquids. Chem. Rev. 114, 1289-1326 (2013).

18. Cai, Y. e. a. Energy-efficient desalination by forward osmosis using responsive ionic liquid draw solutes. Environ. Sci.: Water Res. Technol. 1, 341-347 (2015).

19. O'Neil, M. J. in The Merck index: an encyclopedia of chemicals, drugs, and biologicals (RSC Publishing, 2013).

20. EPA, U. Secondary drinking water standards: Guidance for nuisance chemicals. Drinking Water Contaminants-Standards and Regulations (2017).

21. Straatsma, T.P. \& McCammon, J. A. Computational Alchemy. Annual Reivew of Physical Chemistry 43, 407 (1992).

22. Stanton, R. V., Hartsough, D. S. \& Merz Jr, K. M. Calculation of solvation free energies using a density functional/molecular dynamics coupled potential. J. Phys. Chem. 97, 11868-11870 (1993).

23. Gude, V. Exergy Evaluation of Desalination Processes. ChemEngineering 2, 28 (2018).

24. Alotaibi, S., Ibrahim, O. M., Luo, S. \& Luo, T. Modeling of a continuous water desalination process using directional solvent extraction. Desalination 420, 114-124 (2017).

25. Miller, J. E. Review of water resources and desalination technologies. (2003).

26. Rajvanshi, A. K. Large scale dew collection as a source of fresh water supply. Desalination 36, 299306 (1981).

27. Darwish, M. \& Al-Najem, N. M. Energy consumption by multi-stage flash and reverse osmosis desalters. Appl. Therm. Eng. 20, 399-416 (2000).

28. Hamed, O. A. et al. Thermal performance of multi-stage flash distillation plants in Saudi Arabia. Desalination 128, 281-292 (2000).

29. Younos, T. \& Tulou, K. E. Energy needs, consumption and sources. Journal of Contemporary Water Research \& Education 132, 27-38 (2005).

30. Voutchkov, N. Energy use for membrane seawater desalination-current status and trends. Desalination 431, 2-14 (2018). 